\title{
"El Pasado, la Memoria, el Olvido. Ocho Ensayos de Historia de las Ideas", por Paolo Rossi
}

Nueva Visión, Buenos Aires, 2003. Traducción: Guillermo Piro.

Original en Italiano: Il passato, la memoria, I'oblio. Otto saggi

di storia delle idee. Año 1991-2001.

Reseña: Claudia Neil: "Las escenas de la memoria".

Reseñar esta obra de Paolo Rossi no deja de ser un desafío en tanto nos aproximamos a un texto que, desde la Historia de las ideas y la Filosofía, trata sobre uno de los fenómenos culturales, políticos y académicos más sorprendentes de los últimos años: el surgimiento de la memoria como preocupación central de las sociedades occidentales. Esta tendencia acentuada en la segunda mitad del siglo XX se ha puesto de manifiesto en lo que podríamos denominar los ritos del no-olvido: la rememoración, la recuperación, el inventario multiplicado. Esta tendencia ha involucrado - de manera diversa- a sociedades y grupos, tanto en lo que hace a las instancias de decisión política, mediática y cultural, como a las prácticas comunitarias, las producción académica y la experimentación artística.

Relatos, testimonios, historias de vida, anecdotarios, grandes conmemoraciones, archivos memoriales informáticos, proyectos de museificación, monumentos, exhibiciones, fondos de investigación específicos para programas de estudio y proyectos de investigación, son sólo algunas de las manifestaciones de esta revisión del pasado. Aunque los modos y los medios de la memoria difieran según los casos (grupos, instituciones, naciones, estados, etnias) los conflictos contemporáneos sobre cómo recordar un pasado traumático de genocidio y opresión racial, dictadura y esclavitud, se destacan en la cultura de la memoria en los comienzos del nuevo milenio.

No obstante, y aún reconociendo que la problemática de la temporalidad se ha convertido en un tema de creciente interés y relevancia social, política y estética, no es menos cierto que el problema de la memoria se ha constituido en los últimos años en un tópico de creciente interés académico, un espacio intelectual de variada y creciente producción, "un floreciente campo de estudio" según las palabras de P. Rossi. Tal como el autor lo comenta en su prólogo a la segunda edición del año 2000: “en los años '80 cuando estalló el interés de los estudiosos de todo el mundo por el tema de la memoria, y se volvió uno de los argumentos de más apasionada discusión en la cultura general y en la reflexión política, mi libro comenzó a circular no sólo entre los especialistas", reconociendo incluso que "en la década de los '50 éramos muy pocos los que nos ocupábamos de estos temas".

El interés por el pasado encuentra en los años '60 del siglo XX un momento de gran impulso, en tanto discursos de la memoria de nuevo cuño surgieron en Occidente. Este surgimiento se debió, en gran parte, al traumático proceso de descolonización y al surgimiento de los nuevos movimientos sociales, que en la construcción de su identidad, requerían historiografías alternativas y revisionistas.

En un proceso paralelo, la búsqueda de otras tradiciones -la de los "otros"- 
vino acompañada a una profunda recodificación del pasado. Así, las temáticas de las temporalidades diferenciales y de las modernidades que se dan a diferentes ritmos surgieron como claves para una comprensión nueva y rigurosa de los procesos de globalización en curso.

Posteriormente, en los años ' 80 , los discursos de la memoria se intensificaron en Europa y EE.UU. "Aniversarios alemanes" asociados a la $2^{\circ}$ Guerra Mundial, la caída del Muro de Berlín en 1989, la reunificación de Alemania en 1990, fueron algunos de los eventos que desencadenaron un encendido debate entre historiadores europeos y una intensa cobertura en medios internacionales que reavivaron codificaciones posteriores a la Segunda Guerra y de la historia nacional en Francia, Australia, Italia, Japón, incluso en EE.UU. Ya en los '90, la recurrencia de las políticas genocidas en Ruanda, Bosnia y Kosovo confirmó el creciente interés de la cultura de la memoria en los ámbitos públicos y académicos, lo que explica, de algún modo, el proceso de lo que podríamos denominar "la globalización" de la memoria.

Las resonancias de la memoria del Holocausto constituyeron quizá el más importante estímulo para la discusión pública y la producción académica respecto de las problemáticas de la memoria. El debate cada vez más amplio sobre el Holocausto (desencadenado en gran medida por la serie televisiva Holocausto y, un tiempo después, por el auge de los testimonios), el Museo del Holocausto de Washington, planificado durante la década del '80 e inaugurado en 1993, constituyen, aunque no los únicos, los acontecimientos que concurrieron a la movilización y reflexión intelectual sobre la incapacidad de las sociedades actuales de vivir en paz, sobre el fracaso del proyecto de la Ilustración, sobre el fracaso de la civilización occidental para ejercitar la anamnesis.

Quizá estemos en condiciones de afirmar que esta tendencia (para Rossi una particular "moda por el pasado", con todas las ventajas y peligros que esto implica) habla más bien del presente que del pasado, y de los particulares modos en que ese presente se configura conflictivamente para sujetos y comunidades. Es probable también que esta disposición hacia el pasado muestre una tensión cultural, una insatisfacción causada quizá por una sobrecarga en lo que hace a la información y la percepción, y a una aceleración cultural que ni nuestra psiquis ni nuestros sentidos están preparados para enfrentar. Como plantea Andreas Huyssen "cuanto más rápido nos vemos empujados hacia un futuro que no nos inspira confianza, tanto más fuerte es el deseo de desacelerar y tanto más nos volvemos hacia la memoria en busca de consuelo". ${ }^{1}$

No obstante, y aun reconociendo que el mundo se esta musealizando, todos nosotros desempeñamos algún papel en ese proceso. Si la meta parece ser, como dice Huyssen, "el recuerdo total": ¿qué elementos se ponen en juego en ese deseo de traer todos estos diversos pasados hacia el presente?; ¿qué elementos específicos activan la estructuración de la memoria y, en última instancia, reestructuran la temporalidad en nuestros días?; ¿¿de qué manera se experimentaba el tiempo, la memoria, el olvido en épocas pasadas?

Desde una perspectiva histórica evidente, en el intento de contribuir de manera decisiva en la historia de las ideas, Rossi intenta dar respuestas a estos interrogantes con una obra "clásica e insustituible" según las palabras de Umberto Eco. "El pasado, la memoria, el olvido", editado por primera vez en su versión italiana en 1991, es el resultado de 30 años de trabajos de investigación, análisis y reflexión que Rossi desarrolló sobre la historia de las artes de la memoria en la cultura europea para presentar en este libro una demostración acabada de la historicidad de la memoria y el pasado, y la importancia que ha tenido en tiempos de la edad media y el renacimiento europeos la "cultura de las imágenes." 
El libro se presenta como una recopilación de ocho capítulos, seis de los cuales fueron publicados individualmente en distintos medios académicos entre $1960 \mathrm{y}$ 1980, a partir de los cuales el autor desarrolla una de las tesis centrales que recorre todo el trabajo: "Tal vez, y a pesar de todo lo que se habla de la memoria, hemos subestimado la fuerza de las imágenes. Entre otras cosas porque absolutamente equivocados, creímos que sólo la nuestra, y no en cambio también aquella que está a nuestras espaldas, es definible como una cultura de las imágenes".

Poseedor de una erudición admirable, Rossi muestra, analiza, explica, reflexiona sobre el fantástico universo de las mnemotecnias antiguas, renacentistas y barrocas y devela de un modo sorprendente los elementos constitutivos de una cultura que acuñó tempranamente el sueño enciclopédico de construir grandes Teatros del Mundo. La originalidad del trabajo de P. Rossi es, justamente, examinar y poner en evidencia las relaciones que ligan ese mundo desaparecido con los problemas del hombre de hoy. Curiosamente, y como puede leerse en uno de los capítulos "El arte de la Memoria: Renacimiento y Transfiguraciones", las imágenes construidas para recordar entre los siglos XVI y XVII, vuelven a aparecer hoy en las escuelas para los operadores publicitarios y los teóricos del marketing, verdaderos gurúes de la sociedad capitalista global. De la lectura de esta obra podríamos entonces preguntarnos si acaso el arte de la memoria (tan vigente, tan de moda en la cultura contemporánea), es verdaderamente una suerte de fósil intelectual, o bien ha sufrido una serie de renacimientos y transfiguraciones a lo largo de los últimos cuatro siglos.

En la segunda edición de esta obra del año 2000, edición que se toma como base para su traducción al español, el autor incorpora dos breves capítulos, de los cuales uno constituye una verdadera novedad. El capítulo 7, "La memoria, el cerebro, los inmunólogos", intenta según las palabras de su autor "saldar una deuda que había contraído conmigo mismo" respecto de la rígida separación entre las dos culturas. Rossi critica los modos en que filósofos y literatos han configurado la relación naturaleza-cultura y ciencias naturales-ciencias del espíritu en los primeros años del siglo $\mathrm{XX}$ y la manera en que han dictado las normas sobre el modo en que debe plantearse esa relación. La incorporación de este capítulo constituye un interesante aporte para comprender el modo en que "personas que estudian nuestro cuerpo" utilizan el término memoria para analizar las huellas del pasado y develar la historia de la especie. Desde esta perspectiva el autor propone incluso preguntarse (o seguir preguntándonos) la manera en que esta compleja relación ha sido teorizada.

Un comentario especial merece el capítulo 6 en el que el autor se dedica a analizar de manera profunda y crítica la tensión intrínseca e ineludible entre memoriaolvido a partir de la relación historia-ciencia. Éste es, a mi juicio, uno de los temas relevantes y probablemente de ineludible lectura para todos aquellos que intentan acercarse a la ciencia desde una perspectiva histórica amplia y diversa. Para P. Rossi la ciencia moderna constituye uno de los mejores ejemplos de lo que ha denominado "los modos del olvido", en tanto según las palabras de T. Kuhn "a diferencia del arte, la ciencia destruye su pasado". La naturaleza innovadora de la ciencia, la afirmación de la necesidad de olvidar el pasado, la predilección por lo "nuevo" enfrenta a los historiadores a una empresa difícil y desafiante, porque al momento de analizar esa multiforme actividad a la cual se han dedicado aquellos a los cuales se les ha atribuido, en el siglo XIX, el nombre de "científicos" "el historiador asume como objeto privilegiado un campo del saber en el cual la dimensión del olvido no es marginal sino constitutiva y esencial". En este capítulo P. Rossi pone en discusión, desde una perspectiva filosófica e histórica, uno de los temas y problemas fundamentales del conocimiento. Temas que reconocen una vigencia innegable en 
los ámbitos académicos contemporáneos, tópicos que se mueven siempre en los límites de las fronteras disciplinares y han sido ampliamente discutidos durante todo el siglo XX: la idea de progreso, el modo en que la ciencia se transforma, los cambios de teorías, las prácticas sociales, las instituciones científicas, la naturaleza del conocimiento.

El Pasado, la Memoria, el Olvido es un libro ineludible y diría casi necesario para todos aquellos que, interesados por la historia y la memoria, reconocen en estos conceptos una resonancia ética, política y filosófica. No sólo para los profesionales de la academia sino para el público más amplio que reconoce los infinitos usos del pasado y la memoria, para todos los que encuentran en ella una posibilidad democratizadora. Un texto inevitable para los que intentan poner remedio al olvido natural de los seres humanos ocupados en su cotidiano presente, para todos los que intentan conservar y permitir que sea utilizado un rico patrimonio de tradiciones, de instituciones, de ideas. Para quienes intentan crear un lazo entre las distintas generaciones; para aquellos que luchan por dar lugar y forma a la memoria colectiva. Como dice P. Rossi: "Esa memoria colectiva, a la cual la actividad de los historiadores y de los antropólogos hace una contribución notable, en general es entendida como posibilidad de referirse a un pasado dotado de sentido: algo que puede poner sólidos diques de contención a los procesos de disgregación, quebrantamiento, aislamiento, erradicación de su ambiente y de su pasado de los individuos y las comunidades".

\footnotetext{
${ }^{1}$ Huyssen, Andreas: "En busca del tiempo Futuro", http://www.cholo nautas.edu.pelpdflHuyssen.pdf
} 